\title{
Types of Asymmetries in Exporter-Importer Relationships and Alignment Behaviour
}

\author{
Cagri Talay $^{1} \&$ Volkan Alptekin ${ }^{2}$ \\ ${ }^{1}$ Nottingham Trent University, United Kingdom \\ ${ }^{2}$ Celal Bayar University, Turkey \\ Correspondence: Cagri Talay, Nottingham Trent University, United Kingdom. E-mail: cagri.talay@ntu.ac.uk
}

Received: May 2, 2016 Accepted: May 19, 2016 Online Published: May 24, 2016

doi:10.5539/ijms.v8n3p76 URL: http://dx.doi.org/10.5539/ijms.v8n3p76

\begin{abstract}
The purpose of this paper is to explore the phenomenon of asymmetry in international supply chain relationships and investigate how small exporter firms manage these asymmetric relationships. Prior studies have conceptualized asymmetry as a relationship attribute and concentrated on causal effects of asymmetry in supplier-buyer relationships by highlighting the extensive amount of reasons why asymmetry occurs in dyadic relationships. However, those extensive reasons intent to articulate why asymmetry occurs in relationships, have not provided enough in-depth to understand the complexity of asymmetry in international supply chain relationships, therefore, this study aims to explore the concept of asymmetry by focusing on structure and exercise rather than simply discovering reasons. This research explores the four distinguishable types of relational asymmetry between exporters and importers suggest different implications for international supply chain relationships. As opposed to the existing literature, which has considered and largely agreed that asymmetry is related to a negative connotation, this research suggests that different types of asymmetries also have a positive relational outcome for small export firms. This exploratory paper provides managers with additional insight into the types of asymmetry in international supply chain relationships and suggests that asymmetric relationships must be examined carefully in order to overcome difficulties that distract long-term relationships.
\end{abstract}

Keywords: alignment, asymmetry, export, textile, supply chain, Turkey

\section{Introduction}

Managing supply chain relationships continue to be challenging for firms as they have to work with other companies from different cultures and organisational structures. Increasing pressure of relationships becomes more evident when the companies offer products and services to please their partners. This may also involve changing work routines, adaptation, information exchange, cost adjustment and managerial and strategic objectives. All these changes need to be done to enable them to achieve better results than those which cannot be achieved without a powerful partner (Dyer \& Singh, 1998). However, the existence of asymmetry in dyadic relationships limits the ability of a partner to achieve its own objectives fully, and the stronger party will have more benefit from asymmetric relationships while the weaker party is pushed to be more committed (Johnsen \& Ford, 2002). Such relationships become more prevalent in international supplier-buyer relationships; small export firms may be controlled and limited by power asymmetry in relationships when they enter international exchanges. Paradoxically, a greater number of small firms involve international exchange relationships through asymmetric relationships with strong importers reflecting on the rapid increase of world export volumes that have been well documented by (WTO Secretariat, 2011).

Exporting has been considered as one of the most appropriate mechanisms to access foreign markets for resource poor small firms and facilitate international exchange through developing relationships with foreign buyers (Leonidou, 2003; Leonidou \& Katsikeas, 2010). On the other hand, sustaining competitiveness for importers in their markets becomes challenging, while the demand of consumers is on the increase, which may attract many firms to take action for market entry and has led foreign buyers to establish sustainable collaborations with suppliers through power structures in their relationships (Mentzer et al., 2000; Kotler \& Armstrong, 2004; Rogers \& Leuschner, 2004). These developments in the global marketplace have emphasized the importance of maintaining long-term international supply relationships (Hakansson \& Snehota, 1990; Axelson \& Easton, 1992) 
but also draw attention to the diverse characteristics of those power mediated relations and more importantly the asymmetric power relations (Tokatli, 2006). In addition, power asymmetry as a construct in business-to-business relationships has been paid less attention, and the analysis has not demonstrated substantial understanding of its structure (Nyaga et al., 2013; Hingley, Angel, \& Lindgreen, 2015). There are those that view the concept of power asymmetry, demolish the sustainable exchanges in business relationships and collaboration, however, sustainable exchange relationships can be established through trust and co-operation (Doney \& Cannon, 1997; Pole \& Haskell, 2002). In the next section, this study will discuss critical and conflicting views of power asymmetry.

\section{Positives and Negatives of Power Asymmetry}

Power asymmetry in supply chain relationships has been studied by a number of researchers (Johnsen \& Ford, 2008; Lee \& Johnsen, 2012; Nyaga et al., 2013; Rindt \& Mouzas, 2015). They found that the strong partner influence the weaker partner in two areas mainly; the strategic and operational areas in relationships. This means that up to a certain degree the weaker party allows the control of the stronger party in its business activities (Johnsen \& Ford, 2008). Furthermore, it may make available more chance to take for the stronger party to utilize opportunity from the relationship (Nyaga et al., 2013).

In fact, previous studies of supplier-buyer relationships have explored a variety of constructs in international supplier-buyer relationships including adaptation, commitment, conflict, and distance (Hakansson, 1982) and mutuality, particularity, conflict, interpersonal inconsistency, cooperation, intensity and power and dependence (Johnsen \& Ford 2008). On the same line as those explorations, power has been considered the main determinant in asymmetrical relationships and causes imbalances because importers were the dominant party due to their high level of market knowledge, competencies and position in the exchange relations compared to smaller exporters (Leonidou \& Kaleka, 1998; Katsikeas \& Piercy, 1990; Leonidou, 1989a, 1989b). Moreover, imbalanced relationships were considered to be unsteady and short-termed (Kumar et al., 1995). Others argued that imbalanced power had a destructive effect on efficient relationships by destabilizing cooperation and trust (Pole \& Haskel, 2002), threaten the sustainability of relationships (Gummesson, 1999), and create a negative influence on relationship quality (Naude \& Buttle, 2000). Hence, power imbalance in supplier-buyer relationships has been viewed as (a) harmful in all relationship dimensions; (b) has had a serious impact on trust (Kumar, 1996; Kumar, Scheer, \& Steenkamp, 1998); and (c) that the power of the dominant party tends to weaken the other party (Johnsen \& Ford, 2002). On the other hand, weaker parties can gain power and overcome asymmetries as the relationship develops through different alignment approaches (Lee \& Johnsen, 2012).

Furthermore, Cook \& Emerson (1978) stated that the long-term effectiveness of power can be seen as a control mechanism. Indeed, they were of the opinion that the powerful party will exploit the weaker party meaning that there is imbalanced power in the relationship, thus resulting in less cooperation and high levels of conflict (Dwyer et al., 1987).

In contrast, Gundlach \& Cadotte (1994) stated that power asymmetry in relationships did not always have a negative impact. Although power asymmetry could affect behaviour, communications, perceptions, and sensitivity of relationship partners, and relationship quality, it is not necessary that a business relationship is based on symmetrical power balance (Nyaga et al., 2013, Earp et al., 1999, Kalafatis, 2000). Furthermore, Hingley (2005) supports this and argues that imbalanced power in most cases cannot be a barrier to developing a relationship; indeed, the relationship may provide mutual benefits which override any possible harmful effects of the power imbalance. For a weaker firm, there appears to be a certain degree of tolerance toward an imbalance of power and in some cases, power imbalance has stabilised relationships (Lawler et al., 1988; Rubin \& Brown, 1975). For instance, Ford et al. (1987) identified that in the early export stages, exporters were content to allow control over production and marketing, which helped the exporters to develop certain competencies, which then strengthened ties between partners. However, further research is required that builds an understanding of how asymmetry affects the nature and longevity of relationships (Leonidou, 2003; Anderson \& Kumar, 2006; Hingley, 2005; Cieslik, Kaciak, \& Welsh, 2010) and imbalanced relationship development remains a relatively under-explored area in the literature (Andersen \& Kumar, 2006). Moreover, it is vital to understand the complexities of managing imbalanced relationships and the alignment behaviour of SMEs that may impact upon the relationship dynamics and mutual benefits in relationships with importers. Thus, the recent studies focused on power as a determining concept in dyadic relationships (Nyaga et al., 2013; Hingley, Angel, \& Lindgreen, 2015).

Therefore, the aim of this paper is to explore the asymmetric relationships in international supply chain relationships and identify types of asymmetries in particular. In relation to these, it will investigate how small 
exporter firms manage these different types of asymmetries in international exchange relationships. The context for this research is the Turkish textile sector. As the world's second largest clothing exporter (Tokatli \& Kizilgun, 2009), Turkish textile and apparel exporters have developed key managerial and interaction competencies that have enabled strong partnerships with other geographically distanced buyers and Tokatli \& Kizilgün (2009) question the sustainability of these competencies. Using a multiple case study in Turkey, this paper seeks to understand what type of asymmetries exists in relationships between exporters and importers and how small exporters manage these asymmetries and the alignment behaviour.

\section{Power in Exporter-Importer Relationships}

One party's goal depends on upon the other party's actions, in other words, power stems from another party's dependence (Emerson, 1962; Gadde \& Hakansson, 2002, p. 106). Cox et al. (2001) stated that power deserves to be the central construct in buyer-seller relationships because there is no organisation which can survive alone in the complex business environment (Hakansson \& Snehota, 1990).

Asymmetry in buyer-supplier relationships will cause more difficulty for small suppliers. These problems range from establishing trust and its effect on commitment in particularly long-standing relationships as well as governance of joint ventures (Sollner, 1999; Chen \& Chen, 2002). Inter-organisational relationship studies, resource-based views, and transaction cost theory appear to have paid the most attention to imbalances in inter-organisational relationships. With regards to the resource based view, Chang \& Gotcher (2007) have pointed out that in subcontracting relationships, strong foreign buyers with famous brand names enter the markets and require the highest amount of relationship-specific investments from weaker suppliers, thus giving more power to foreign buyers including bargaining power and manufacturing control. Therefore, international supplier-buyer relationships are often seen, and foreign buyers use their power. They have suggested that preventing or at least reducing the amount of opportunistic behaviour of foreign buyers and dependence relies greatly on 'relationship learning and relational capital'.

Adaptation has been categorised as both unilateral and bilateral (Hallen et al., 1991). Nevertheless, with regards the adverse effect of asymmetric power in a relationship, it has been found that unilateral adaptation is related to asymmetric power which means that there is a lack of trust established between parties (Brenan et al., 2003). Therefore, the length of relationship may be shorter and unilateral adaptation which results from an asymmetric power will lead to opportunistic behaviour between parties.

Kumar (1996) argued that most manufacturer-retailer relationships are asymmetric. This will make the relationships unstable and a slippery path will result if any errors are made by the weaker party during transactions. Indeed, if this happens, the dominant party will force the weaker party to accept penalising actions, which can result in harmful consequences. Hingley (2005) examined the exercise of the asymmetric power of fresh food retailers and supplier relationships. It was found that asymmetric relationships are obviously favourable for strong retailers and those weaker suppliers do not want to be involved in such relationships.

Small firms may find a way to make business with large buyers by becoming specialised with regards to certain niches in relationships. However, operating in these niches limits the small firms which may result in the loss of strategic flexibility and the relinquishing of individual objectives in order to preserve the relationship. This will require an investment from the small firm. On the other hand, asymmetric power relationships are also against small suppliers because they are under the control of large buyers in the strategic and technical areas. Small firms usually give control to the large buyers and put effort into proving their sufficiency to the large buyers (Johnsen \& Ford, 2008). Furthermore, historic dependence in relationships where asymmetry has taken place could be destructive for small suppliers because with historic dependence it is likely that large buyers may take it for granted with negative consequences often affecting small suppliers (Johnsen \& Ford, 2008).

In international business relationships, export-import firms have been studied by Katsikeas \& Piercy (1990) Leonidou \& Katsikeas (2010). Both researchers found that strong foreign buyers have more authority over small exporting suppliers because foreign buyers have advanced marketing skills, knowledge, and accessibility to large consumer markets. Furthermore, some barriers such as time differences, language, inadequate face-to-face contacts, cultural dissimilarities and distance are extremely critical to relational exchanges within a well-functioning supply chain (Styles \& Ambler, 2003; Leonidou et al., 2006). The uncertainty of environment and internal uncertainty influence exporter-importer relationships. Examples of this include information asymmetries which will lead to opportunistic behaviour and the poor coordination of activities (Hakansson \& Snehota, 1995).

Managerial problems in asymmetric exporter-importer relationships are the main focus of many researchers in the reviewed literature although there are no clear suggestions regarding how small exporting firms can manage 
and overcome asymmetry in their relationships with importers.

\section{Methodology}

A multiple case study approach (Yin, 2003) was selected for this study to provide an in-depth examination of each case and explore types of asymmetries in exporter-importer relationships. Multiple case studies are useful in order to build an understanding of the similarities and differences between the different exporting organisations (Coviello \& Jones, 2004; Easton, 1998; Eisenhardt, 1989; Yin, 1994) and it has also been seen as the most appropriate for supply chain IMP (International Marketing Purchasing Group) research (Leonidou \& Kaleka, 1998; Johnsen, 2007; Johnsen \& Ford, 2006; 2008).

\subsection{Sampling Procedures}

Ten case studies were identified through initial contact with The General Secretariat of the Istanbul Textile and Apparel Exporter Association (ITKIB). Using their database participant firms was identified and the following criterion was set: 1) Companies need to be in the textile industry. 2) Companies need to be a member of (ITKIB) General Secretariat of Istanbul Textile \& Apparel Exporter Association in Turkey. 3) Companies need to involve international business as suppliers, contracted manufacturers or independent exporter and subsidiaries. 4) Companies need to employ a maximum of 250 employees.

All cases were selected from the same industry so as to avoid potential contextual differences in the findings (Metcalf et al., 1992). All cases were located in Istanbul in Turkey to ensure geographical and region-specific economic consistency.

\subsection{Data Collection}

The empirical data collection included a total of twenty semi-structured interviews conducted with small, medium textile exporters in asymmetric relationships with foreign buyer organisations. There were ten in-depth case studies of suppliers in the Turkish textile industry. Within each case study, two interviews were conducted with the owner/director and production or export/sales managers (Table 1).

All interviews were tape recorded and notes were taken, transcribed verbatim, and translated from Turkish into English. An important concern about the translation of interview transcriptions from Turkish into English was that the original meaning of the text was not lost during the translation process. Therefore, the translation process was carefully conducted by the researcher and a second review was requested from the translation office, which is accredited by official bodies in Turkey. Interviews lasted 1 to 1 and a half hour.

The initial contacts with participants from each supplier company were via telephone and e-mail. The areas for discussion related to asymmetric relationships, alignment behaviour and strategies employed by apparel suppliers. In addition to the interviews, other data collection methods were employed, including reviews of company documents and archives, published statistics by official bodies such as, reports, marketing and market related information and facts from the companies' websites. This information was gathered in order to make the researchers more aware of the current state of the case companies and their environments. The researchers studied averaged 7-10 pages of each company's reports, seeking information on companies' past, financial stability, directors and managers' responsibilities. The reports of official bodies in Turkey were reviewed to seek information on the textile industry and textile export and the case companies' positions within the industry ITKIB (2013). Consequently, researchers collected cross sectional data from the ten case studies.

\subsection{Why SMEs}

This paper is designed to explore the alignment behaviour of small apparel suppliers in asymmetric relationships with large buyers. This study followed The EU categorisation of SME definition i.e. those firms with less than 250 employees (European Commission, 2003). The importance of SMEs has been emphasised as SMEs are the engine of growth, poverty reduction and employment provider in developing countries in particular. Moreover, SMEs account for over $95 \%$ of the business population, and are therefore an increasingly dominant form of business organisation in all countries (OECD, 2006).

The Turkish textile and apparel industry was selected as it is one of the major industries in Turkey with 49,000 small and medium enterprises active in this sector (Muneer et al., 2006) Moreover, 7500 of these textile manufacturers are exporters (Kutluksaman et al., 2012). Turkey has become a world leading textile manufacturing hub, growing by 13.8 percent in 2011 and has become the fourth largest textile exporter in the world (WTO Statistics, 2011) producing high value added, quality textiles, contributing 7.2 percent of Turkey's total export provision (ITKIB, 2013). Currently, Turkish exports have a share of 45.2 percent of the European textile market (TIKIB, 2013) 
Turkey has a unique geostrategic position, seen as a bridge between Europe and Asia; east and west, it has good relations with the European Union (Kalafatouglu, 2010). Turkish textiles firms have established business relationships with European organisations and this may shed light on the type of asymmetries in exporter-importer relationships. Moreover, the Export Strategic Plan published by the Turkish Government in 2005 emphasized the importance of competitiveness and sustainability of export activities (Foreign Trade Ministry, 2005, www.dtm.gov.tr). In addition, Turkey is an important emerging market, ranked by the IMF in 2013 as the first in Europe and fourth in the world. From the Turkish perspective, it is crucial to maintaining this competitively, continue to build competencies (Ozkanli \& Durak, 2007; Ural, 2007) and sustain relationships and competencies between Turkish suppliers and international buyers (Tokatli, 2006, 2007; Karadeniz \& Gocer, 2007). In this study, cross-sectional data was collected from the ten case studies. The initial contact with respondents from each export company was via telephone and e-mail. The primary data for this research comprised twenty semi-structured interviews with executives of ten small and medium-sized textile export companies.

Table 1. Case company and respondent profiles

\begin{tabular}{llll}
\hline & Export Supply Chain Position & \multicolumn{2}{l}{ Key } \\
\hline Case A & Manufacturer/Finished Goods & 1. & Export Manager \\
& & 2. & Production Manager \\
Case B & Manufacturer Finished Goods & 3. & Owner/Director of Export Sales \\
& & 4. & Purchasing Manager \\
Case C & Manufacturer/Finished Goods & 5. & Account Manager \\
& & 6. & Owner/Director of Production \\
Case D & Manufacturer/Finished Goods & 7. & Export Finance Manager \\
& & 8. & Production Manager \\
Case E & Manufacturer/Finished Goods & 9. & Owner/Director of Production \\
& & 10. & Export Marketing Manager \\
Case F & Manufacturer/Semi-Finished Goods & 11. & Owner/Director \\
& & 12. & Export Manager \\
Case G & Manufacturer/Semi-Finished Goods & 13. & Owner/Director of Export \\
& & 14. & Production Manager \\
Case H & Manufacturer/Semi-Finished Goods & 15. & Export Marketing Manager \\
& & 16. & Production Manager \\
Case I & Manufacturer of Finished Goods & 17. & Owner/Director of Purchasing \\
& & 18. & Export Sales Manager \\
Case J & Manufacturer Finished Goods & 19. & Owner Director of Production \\
& & 20. & Export Sales/Marketing Manager \\
\hline
\end{tabular}

\subsection{Data Analysis and Analytical Techniques}

As Yin (1994) suggests the analytical strategy follows the stages of "searching, categorising and tabulating". The data from cases was analysed through 'pattern matching' the empirical data with the research questions. Each case was analysed. Data sources were filtered and organised in order to capture the experience of the suppliers and to simplify and build a structure for the findings and matching the patterns with an illustration of the evaluation of asymmetric relationships and alignment behaviour (Collis \& Hussey, 2003).

The unit of analysis was the relationships between small apparel suppliers and large buyers. Conceptual clusters and role-ordered matrices were employed as the process for coding (Miles \& Huberman, 1984) that led to reducing and structuring and data analysis. The researcher focused on transcripts by annotating transcripts to provide first level codes in the analysis process (Miles \& Huberman, 1994). In addition, contextual factors and emerging themes were raised by the respondents were identified in Figure 1. This provided an opportunity for within-case comparison and demonstrated the similarities and differences between respondents' answers in the organisations. Cross-case analysis was used to comprehensive and find patterns of alignment behaviours in the findings (Yin, 1994) enabling the researcher to validate the findings externally, build appropriate theory (Eisenhardt, 1989).

This process created a comprehensive picture of intra and inter-company interpretations and helped to build Types of Asymmetries and Alignment Seeking Behaviour of Exporters in Figure 1. 


\subsection{Research Credibility}

Reliability: Yin (2003) stated that reliability is a replication of a case study by following the identified procedures and protocols in an earlier case study. In addition, developing databases for a case study will enhance reliability because these are internal conditions of any case study research. The important point of replication is not to replicate the findings and conclusions of an earlier case study but to focus on transparency and to demonstrate sense-making during data analysis (Easterby-Smith et al., 2002).

Construct Validity: Yin (2003) has stated that construct validity can be ensured by establishing the right operational set of measures for the concepts being studied. Primary and secondary data were collected through interviews, websites, academic journals and databases and official bodies' databases. Revisiting the literature review and conceptual framework and research progress iteratively and gaining feedback from interview participants about transcripts and conclusions and their thoughts about the completed analysis for each case study.

Internal Validity: Internal validity is important when demonstrating coherence between a relationship approach and following outcomes, irrelevant variables and bias should be removed from the research design to ensure that internal validity is provided (Easterby-Smith et al., 2002). Interviews which were consistent with the focus of research and provided alteration in the research instruments

External Validity: Analytic generalization is the focus of a case study; therefore, analytic generalisation is about generalising concepts and theories and, in so doing, a generalisation of the results to broader theory (Yin, 2003). Conducting ten case studies provided the opportunity for generalisation; thus, external validity was toughened. Furthermore, the findings were bridged with the literature and that also provided the opportunity to understand differences between the literature and the findings.

\section{Model Overview}

Respondents in the study were exceedingly familiar with the phenomenon of asymmetry in supply relationships with importers and the management of these relationships. In fact, many of the managers have never experienced symmetry in supply chain relationships. A few managers have experienced symmetry but it did not last long. In response to the question about how a company would describe its relationship with an importer, one respondent replied, 'it is difficult enough for us, this is the way we survive and learn, there is no other option available at the moment'.

Due to their experience with asymmetry in their relationships with importers, respondents were able to describe how to recognize, analyse and make strategic managerial decisions in their relationships. Based on the comments of respondents through pattern matching of asymmetric relationships in data analysis, the process was revealed (Figure 1). In brief, all respondents wished to have more symmetric relationships and less power exerted by importers.

As the process model illustrates in Figure 1, two primary steps, recognition and analysis need to be taken by managers before making strategic decisions and employing managerial behaviour. Two groups of key findings emerged from analysis of the comments of respondents about asymmetry in relationships; there are two different types of asymmetries (Figure 1) they are satisfactory asymmetry and unsatisfactory asymmetry. Secondly, the findings suggest that there are four types of alignment modes employed by small export firms when managing asymmetric relationships, which are beneficial, manageable, adaptable and unbearable.

Recognition is the first stage in the process of alignment seeking. In this stage, export managers understand the nature of the relationships that they have been through by considering the positives and negatives of the relationship. They also consider whether or not the relationship will it add more to their current state and whether or not it will add more to a future state. One initial business objective for all respondents of export firms is to achieve long-term relationships with importers. Therefore, recognizing the level of asymmetry is an important indicator as to whether or not it is satisfactory or unsatisfactory and whether or not the asymmetry is deemed to be advantageous to the export firm in the long run. Hence, the findings suggested that two distinguishable levels of asymmetry, satisfactory and unsatisfactory, are evident in relationships.

Analysis of initiates is the second stage which is the process of adapting a type of alignment. In this stage, exporters develop a deeper understanding of their relationships with importers by evaluating the grand requirements of importers and checking them against their own capabilities, resources, and business objectives. For example, they check if the asymmetry is satisfactory or unsatisfactory, how satisfactory it is, to what degree an unsatisfactory asymmetry can be taken, does it really serve and provide long-term bonding? Therefore, the findings suggest that beneficial satisfactory asymmetry offers a desirable level of asymmetry for exporters so that 
they can achieve some degree of symmetry in relationships with importers. There is more room for negotiation and involving bilateral innovative activities that support the interaction capabilities of export companies and facilitate longer relationships.

Manageable satisfactory asymmetry offers slightly less involvement with bilateral innovative activities and negotiations but provides a stable base for interaction capabilities and continuation of relationships with an importer. Most activities are conducted according to negotiated plans and procedures. On the other hand, adaptable unsatisfactory asymmetry offers an undesirable level of asymmetry because more commitment and investment from small exporters are required. There is no opportunity for negotiation and involving innovative activities but necessary adaptations to meet the requirements of an importer still provide some learning for the exporter. But the cost of this relationship is almost the same as the level of return for the exporter. In this situation, initial objectives of export firms are achieved in principle terms but not in financial terms. In unbearable unsatisfactory asymmetry, it is evident that an exporter does not have a chance to survive in the relationship because the cost is much higher than the return. Therefore, it is a relationship with death.

After analysing the asymmetry in relationships, findings indicated that small export firms have eight different managerial behaviours in order to align with importers in asymmetric relationships. These alignment forms are; demonstrate, involve, negotiate, maintain, agree, satisfy, cope and fit. If a manager's toleration of certain degrees of power asymmetry in relationships with importers is high, a satisfactory approach in order to align with the importer will be adopted (Figure 1). On the other hand, if a manager cannot tolerate a certain degree of power asymmetry in relationships with importers, an unsatisfactory approach in a relationship with importers will be adopted (Figure 1). If there is no chance to go further in asymmetric relationships, export managers adapt an unsatisfactory unbearable asymmetry.

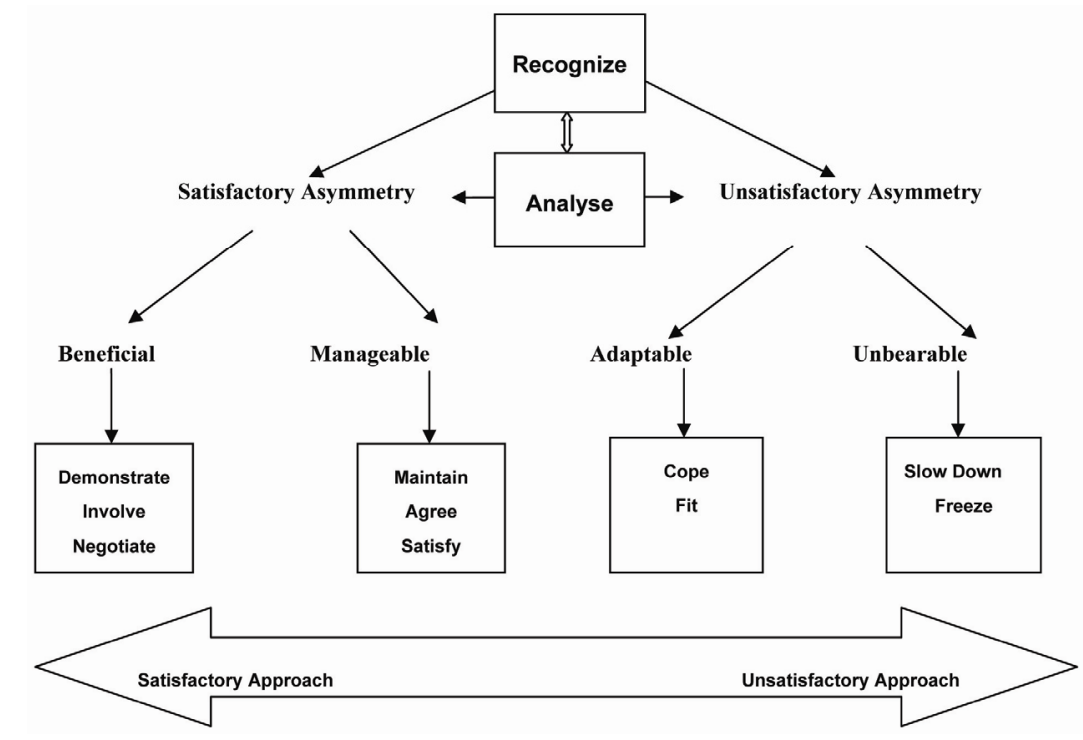

Figure 1. Types of asymmetries and alignment seeking behaviour of exporters

\section{Discussion}

This paper examines the characteristic of asymmetric exporter-importer relationships and how small exporters manage these asymmetries in their relationships. Earlier studies on asymmetric relationships have demonstrated that asymmetry is an important determinant for the nature of relationships. It provides potential for both parties to achieve their desired outcomes in their relationships (Hingley, 2005; Johnsen \& Ford, 2008; Johnsen et al., 2008).

In accordance with the existing literature that has investigated issues related to asymmetry in dyadic relationships, some researchers have the same opinion that asymmetry is an important construct that can create barriers for the success of the relationship (Kumar et al., 1995; Pole \& Haskel, 2002). On the other hand, that can provide some opportunities for the success of relationships Hingley (2005). However, there is still not a comprehensive agreement in the literature and consistent empirical support in industrial marketing studies. For example, some exporter-importer relationships lasted longer while some exporter-importer relationships broke up. This has suggested that in-depth investigation to explore the multifaceted character of asymmetry is needed 
(Lee \& Johnsen, 2012; Nyaga et al., 2013; Hingley, Angel, \& Lindgreen, 2015). This research has addressed this gap in the literature and it built on the work of IMP interaction approach and asymmetry investigation of Johnsen \& Ford (2008). This study has found four types of distinguishable asymmetry in the context of international exchange relationships. According to this empirical investigation, these asymmetry types are beneficial satisfactory asymmetry, manageable satisfactory asymmetry, adaptable unsatisfactory asymmetry and unbearable unsatisfactory asymmetry. These four asymmetry types influence on exporter-importer relationships differently, thus small export firms adopted different strategies for each of them.

The existing literature highlighted the main reasons and negative influence of asymmetry on dyadic relationships, were investigated. For example, beneficial satisfactory asymmetry is not naturally negative for small export firms; it is actually one of the preferred options in order to involve international exchange relationships to different degrees. If an exporter and importer agree with the structure of relationships, it is beneficial for both. Here, the benefits for exporters are that they can demonstrate, involve and negotiate. This indicates that a satisfactory approach is adopted by exporters. These strategies are consistent with the construct of mutuality that is at an ideal level in creating equilibrium in asymmetric relationships (Ford et al., 1986). On the other hand, manageable satisfactory asymmetry also has positive and negative dimensions. These are stability, less risk taking and standard capability development but less involvement in strategic decisions and negotiations. This indicates that a satisfactory approach is still adapted by an exporter. These strategies are; maintain, agree and satisfy consistent with the construct of cooperation which is desirable for smaller suppliers in the exploratory stage of asymmetric relationships, but this was not the interest of larger customers (Lee \& Johnsen, 2012). Lastly, adaptable unsatisfactory asymmetry may yield either a positive or negative influence on dyadic relationships depending upon the degree of tolerance by exporters. In this asymmetry type, exporters can still maintain the status quo with no involvement in strategic decisions by an importer and there may be no financial gain from the relationship., This indicates that an unsatisfactory approach adopted by exporters, coping and fitting consistent with the construct of power, could be coercively employed and dependence encouraged in relationships in order to control a small supplier (Frazier \& Antia, 1995; Hausman \& Johnston, 2010).

\subsection{Managerial Implications}

This study may provide guidance for managers when they form their business relationships with foreign buyers. The key contribution of this research shows what types of asymmetry they would have in their relationships and how they should focus on where there is dissimilarities on each asymmetry types (beneficial, manageable and adaptable). This study may also influence their market entry mode considerations and strategic decision making through networks of relationships with foreign buyers.

Overall, this study discloses that exporter suppliers do not make internationalisation decisions based on relationship evaluation. Therefore, this study is also important for exporter suppliers to improve their critical understanding and awareness of asymmetric relationships. Moreover, how to manage asymmetries in relationships and gain better positions, develop better capabilities and contribute to the relationships in order to be nominated suppliers in the eye of foreign buyers. This involves export suppliers thinking about the possible commitments and liabilities for their foreign customers. This also involve considering training and management systems adoption to develop differentiated and flexible approaches for managing asymmetric relationships in different circumstances.

\section{Conclusion}

All in all, the findings of this research suggest that asymmetry is multifaceted and export firms employ different strategies to address the potential relationship performance implications of each relationship. In addition, the findings from this study demonstrated that asymmetry may be changed over time. Therefore, unsatisfactory asymmetry can be evolved from satisfactory asymmetry. This temporal and dynamic nature of alignment seeking behaviour of export managers has an axis with TCE (Transaction Cost Economics) (Williamson, 1985; Williamson et al., 1975). Indeed, the central phenomenon of this study may have a specific application of TCE in an exporter-importer context in international exchange relationships. In fact, when export managers realize and re-analyse their relationships, and experience a higher degree of satisfaction in relationships, they can adapt a satisfactory approach with minimum transaction costs.

This research implication provides a greater understanding of the overlooked field of dyadic relationship research. Although asymmetry is a common construct in most dyadic relationships in both the local context and international context, a theoretical framework addressing how export managers overcome imbalanced relationships has been paid limited attention. Seeking a satisfactory alignment approach in asymmetric relationships fills this gap in the existing literature. The rich qualitative data collection through interviews 
provided substantial descriptions of contextual situations and supported the extension of the scope of relational theories and related relational constructs.

This study also provides some more questions that can offer new research opportunities. For example, similar research can be conducted for different industries and sectors in order to investigate a broader perspective of asymmetry types and categories, and how small firms manage different asymmetries in their relationships. Furthermore, how the capability development of small firms influences asymmetric relationships in different industries is also an interesting area to research in conjunction with resource-based view. Lastly, how asymmetry influences market entry of small export firms and different alignment seeking behaviour can be adapted. This research also provides a guide for export managers for self-assessment of their company and relationships with importers. While managing international business relationships adds more pressure on small firms it is considered the most valuable business attempt that supports the economy of countries by making a balance of account deficit as shown in the Export Strategic Plan published by Turkish Government in 2005 which emphasized the importance of competitiveness and sustainability of export activities (Foreign Trade Ministry, 2005, www.dtm.gov.tr). In addition, export managers also apply the concepts of asymmetry through a relationship segmentation process. Satisfactory and unsatisfactory approaches can offer an insight as to what degree the resources should be allocated and committed for relationships, and what degree of tolerance should be adapted. With strong justification, termination could be assigned to stop relationships, while the transition cost is lower.

As previously highlighted in the existing literature, asymmetry is harmful and has negative consequences. The framework of alignment seeking behaviour of exporter offers two ways of alignment; satisfactory and unsatisfactory. Both approaches support and refuse these claims. Because these claims do not take time progression into consideration, therefore, asymmetry has been seen as harmful with negative consequences. However, for most export firms the asymmetry is adaptable in the early stages of their relationship stage and this may evolve as beneficial and manageable later. This critical insight supports an understanding of why exporter-importer relationships last longer or collapse.

The asymmetric relationship literature has not been completed in the local context and underdeveloped in the international context. A number of researchers explored the topic and the structural importance of asymmetry was established. Asymmetry has been investigated from different relationship constructs through qualitative research methods including adaptation, commitment, conflict, and distance (Hakansson, 1982) and mutuality, particularity, conflict, interpersonal inconsistency, cooperation, intensity and power and dependence (Johnsen \& Ford, 2008). And a quantitative research found the level of dependence and its significant impacts on a dyadic relationship (Gundlach \& Cadotte, 1994). In this study, how small export firms managed asymmetric relationships was explored with qualitative methods and a management process was discovered. However, there is still a gap in the existing asymmetry literature. Future researchers can consider the evolution of asymmetric relationships during the relationship building stages or the process of involvement into international markets.

\section{References}

Andersen, P. H., \& Kumar, R. (2006). Emotions, trust and relationships development in Business Relationships: A conceptual model for buyer-seller dyads. Industrial Marketing Management, 35(4), 522-535. http://dx.doi.org/10.1016/j.indmarman.2004.10.010

Axelsson, B., \& Easton, G. (1992). Networks - A New way of Reality. London: Routledge.

Brennan, R., Turnbull, P. W., \& Wilson, D. T. (2003). Dyadic adaptation in Business to Business Markets. European Journal of Marketing, 37(11), 1636-1665. http://dx.doi.org/10.1108/03090560310495393

Chang, K. H., \& Gotcher, D. F. (2007). Safeguarding investments and creation of transaction value in asymmetric international subcontracting relationships: the role of relationship learning and relational capital. Journal of World Business, 42(1), 477-488. http://dx.doi.org/10.1016/j.jwb.2007.06.008

Chen, H., \& Chen, T. J. (2002). Asymmetric strategic alliances: a network View. Journal of Business Research, 55(12), 1007-1013. http://dx.doi.org/10.1016/s0148-2963(02)00284-9

Cieslik. J., Kaciak, E., \& Welsh, D. H. B. (2010). The effect of early internationalization on survival, consistency, and growth of export sales. Journal of Small Business Strategy, 21(1), 39-64.

Collis, J., \& Hussey, R. (2003). Business Research: a practical guide. Basingstoke: Palgrave Macmillan.

Cook, K. S., \& Emerson, R. M. (1978). Power, Equity and Commitment in Exchange Networks. American Sociological Review, 43(1), 721-739. http://dx.doi.org/10.2307/2094546 
Coviello, N. E., \& Jones, M. V. (2004). Methodological issues in international entrepreneurship research. Journal of Business Venturing, 19(4), 485-508. http://dx.doi.org/10.1016/j.jbusvent.2003.06.001

Cox, A., Lonsdale, C., Watson, G., \& Sanderson, J. (2001). Power Regimes: A Strategic perspective on the management of Business to Business relationships in supply networks. The paper was published at the 17 th IMP-conference in Oslo, Norway in 2001.

Doney, P. M., \& Cannon, J. P. (1997). An Examination of the Nature of Trust in Buyer-seller Relationships. Journal of Marketing, 61(April), 35-51. http://dx.doi.org/10.2307/1251829

Dwyer, F. R., Shurr, P. H., \& Oh, S. (1987). Developing buyer-seller relationships. Journal of Marketing, 51(2), 11-27. http://dx.doi.org/10.2307/1251126

Dyer, J. H., \& Singh, H. (1998). The relational view: cooperative strategies and sources of inter-organisational competitive advantage. Academy of Management Review, 23(4), 660-679. http://dx.doi.org/10.5465/amr.1998.1255632

Earp, S., Harrison, T., \& Hunter, A. (1999). Relationship Marketing: Myth or Reality. In D. McLoughlin \& C. Horan (Eds.), Proceedings of The 15th Annual IMP Conference, University College, Dublin.

Easterby-Smith, M., Thorpe, R., \& Lowe, A. (2002). Management Research, an introduction. London: Sage Publication. http://dx.doi.org/10.4135/9781412950589.n521

Easton, G. (1998). Case research as a methodology for industrial networks: a realist apologia. In P. Naude \&P. W. Turnbull (Eds.), Network Dynamics in international marketing. London: Pergamon Press.

Eisenhardt, E. M. (1989). Building theories from case study research. Academy of Management Review, 14(4), 532-550. http://dx.doi.org/10.5465/amr.1989.4308385

Emerson, R. M (1962). Power-Dependence Relations. American Sociological Review, 27(1), 31-41.

European Commission (2003). Small and medium-sized enterprises (SMEs) are defined in the EU recommendation 2003/361. Retrieved from http://ec.europa.eu/growth/smes/business-friendly-environment/sme-definition/index_en.htm

Ford, I. D. et al. (1987). Managing export development between industrializedand developing countries. In P. J. Rosson \& S. D. Reid (Eds.), Internationalexport entry and expansion (pp. 71-90). New York: Praeger Publishers

Gadde, L. E., \& Hakansson, H. (2002). Supply Network Strategies. Chichester: John Wiley \& Sons LTD.

Gummesson, E. (1999). Total Relationship Marketing. Oxford: Butterworth Heinemann.

Gundlach, G. T., \& Cadotte, E. R. (1994). Exchange Interdependence and Interfirm Interaction: Research in a Simulated Channel Setting. Journal of Marketing Research, 31(1), 516-532.

Hakansson, H. (1982). International Marketing and Purchasing of Industrial Goods. Chichester: John Wiley \& Sons.

Hakansson, H., \& Snehota I. (1990). No Business is an Island: The Network Concept of Business Strategy. Scandinavian Journal of Management, 4(3), 187-200. http://dx.doi.org/10.1016/0956-5221(89)90026-2

Hallen, L., Johanson, J., \& Seyed-Mohamed, N. (1991). Interfirm Adaptation in Business Relationships. Journal of Marketing, 55(2), 29-37. http://dx.doi.org/10.2307/1252235

Hingley, M. K. (2005). Power to all our friends? Living with imbalanced in supplier retailer relationships. Industrial Marketing Management, 34(8), 848-858. http://dx.doi.org/10.1016/j.indmarman.2005.03.008

Hingley, M., Angell, R., \& Lindgreen, A. (2015).The current situation and future conceptualization of power in industrial markets. Industrial Marketing Management, $226-230$. http://dx.doi.org/10.1016/j.indmarman.2015.03.022

Johnsen, R, E., \& Ford, D. (2008). Exploring the concept of asymmetry: A typology for analysing customer-supplier relationships. Industrial Marketing Management, 37(1), 471-483. http://dx.doi.org/10.1016/j.indmarman.2007.05.004

Johnsen, R. E. (2007). The role of focal suppliers in strategic networks for internationalisation: Perspectives from small and medium sized Italian and Thai silk suppliers. Journal of Fashion Marketing and Management, 11(1), 1361-2026. http://dx.doi.org/10.1108/13612020710734454 
Johnsen, R. E., \& Ford, D. (2002). Developing the concept of asymmetrical and symmetrical relationships: Linking relationship characteristics and firms' capabilities. Proceedings of the $18^{\text {th }}$ IMP Conference, Dijon, France.

Johnsen, R. E., \& Ford, D. (2006). Interaction capability development of smaller suppliers in relationships with larger customers. Industrial Marketing Management, 35(8), 1002-1015. http://dx.doi.org/10.1016/j.indmarman.2006.05.005

Johnsen, R. E., \& Ford, D. (2008). Exploring the concept of asymmetry: a typology for analysing customer-supplier relationships. Industrial Marketing Management, 37(4), 471-483. http://dx.doi.org/10.1016/j.indmarman.2007.05.004

Kalafatis, S. P. (2000). Buyer-seller relationships along channels of distribution. Industrial Marketing Management, 31(3), 215-228. http://dx.doi.org/10.1016/s0019-8501(00)00118-8

Kalafatoglu, T. (2010). Doing business in Turkey helps bridge Europe and Asia. Global Business and Organizational Excellence, 29(3), 61-75. http://dx.doi.org/10.1002/joe.20309

Karadeniz, E., \& Göcer, K. (2007). Internationalization of Small firms, to case study of Turkish small--and medium-sized enterprises. European Business Review, 19(5), 387-403. http://dx.doi.org/10.1108/09555340710818978

Katsikeas, C. S., \& Piercy, N. F. (1990). The Relationship between Greek export manufacturers and UK importers: The dimension of exercised power. Journal of Marketing Management, 6(3), 239-256. http://dx.doi.org/10.1080/0267257x.1990.9964130

Kotler, P., \& Armstrong, G. (2004). Principle of Marketing (10th ed.). USA: Pearson Education.

Kumar, N. (1996). The power of trust in manufacturer-retailer relationships. Harward Business Review, 74(6), 92-106.

Kumar, N., Scheer, L. K., \& Steenkamp, J. B. (1998). Interdependence punitive capabilitiy and the reciprocation of punitive actions in channel relationships. Journal of Marketing Research, 35(2), 225-235. http://dx.doi.org/10.2307/3151850

Kumar, N., Scheer, L. K., \& Steenkamp, J. B. E. M. (1995). The effect of perceived interdependence on dealer attitudes. Journal of Marketing Research, 32(3), 348-356. http://dx.doi.org/10.2307/3151986

Kutluksaman, M., Mutlu, I., \& Unluaslan, E. (2012). Turkey’s Textiles and Apparel Cluster Microeconomics of Competitiveness HBS/HKS Michael Porter. Retrieved from http://www.isc.hbs.edu/pdf/Student_Projects/2012\%20MOC\%20Papers/MOC\%20-\%20Turkey\%20Textiles $\% 20$ and\%20Apparel\%20Cluster.pdf

Lawler, E. J., Ford, R. S., \& Blegen, M. A. (1988). Coercive capability in conflict: A test of bilateral deterrence versus conflict spiral theory. Social Psychology Quarterly, 51(2), 93-107. http://dx.doi.org/10.2307/2786833

Lee, C. J., \& Johnsen, R. (2012). Asymmetric customer-supplier relationships in Taiwanese electronics firms. Industrial Marketing Management, 41(4), 692-705. http://dx.doi.org/10.1016/j.indmarman.2011.09.017

Leonidou, L. C. (1989a). Behavioural Aspects of the Exporter-Importer Relationships: The Case of Cypriot Exporters and British Importers. European Journal of Marketing, 23(4), 17-33. http://dx.doi.org/10.1108/eum0000000000576

Leonidou, L. C. (1989b). The Exporter-Importer Dyad An Investigation. Journal of Managerial Psychology, 4(2), 17-33. http://dx.doi.org/10.1108/eum0000000001713

Leonidou, L. C. (2003). Overcoming the limits of exporting research using the relational paradigm. International Marketing Review, 20(2), 129-141. http://dx.doi.org/10.1108/02651330310470366

Leonidou, L. C., \& Kaleka, A. A. (1998). Behavioural aspects of buyer-seller relationships: their association with export involvement. International Marketing Review, 15(5), 373, 397. http://dx.doi.org/10.1108/02651339810236407

Leonidou, L. C., \& Katsikeas, C. S. (2010). Integrative assessment of exporting research articles in business journals during the period 1960-2007. Journal of Business Research, 63(8), 879, 887. http://dx.doi.org/10.1016/j.jbusres.2010.01.005 
Leonidou, L. C., Barnes, B. R., \& Talias, M. A. (2006). Exporter-importer relationship quality: The inhibiting role of uncertainty, distance and conflict. Industrial Marketing Management, 35(1), 576-588. $\mathrm{http}: / / \mathrm{dx}$.doi.org/10.1016/j.indmarman.2005.06.012

Mentzer, J. T., Foggin, J. H., \& Golicic, S. L. (2000). Collaboration: The enablers, impediments, and benefits. Supply Chain Management Review, (September/October).

Metcalf, L. E., Frear, C. R., \& Krishnan, R. (1992). Buyer-seller relationships: An application of the IMP interaction model. European Journal of Marketing, 26(2), 27-46. http://dx.doi.org/10.1108/03090569210010022

Miles, M., \& Huberman, A. (1984). Qualitative data analysis: a sourcebook of new methods. London: Sage.

Muneer, T., Asif, M., Cizmecioglu, Z., \& Ozturk, H. K. (2006). Prospects for solar water heating within Turkish textile industry. Renewable and Sustainable Energy Review, 12(3), 807-823. http://dx.doi.org/10.1016/j.rser.2006.10.024

Naude, P., \& Buttle, F. (2000). Assessing Relationship Quality. Industrial Marketing Management, 29(4), 351-361. http://dx.doi.org/10.1016/s0019-8501(00)00112-7

Nyaga, G. N., Lynch, D. F., Marshall, D., \& Ambrose, E. (2013). Power Asymmetry, adaptation and collaboration in dyadic relationships involving a powerful partner. Journal of Supply Chain Management, 49(3), 42. http://dx.doi.org/10.1111/jscm.12011

OECD (2006). The OECD Bologna Process on SME \& Entrepreneurship Policies, Istanbul SMEs 2006. Retrieved from http://www.insme.org/files/The\%20OECD\%20Bologna\%20Process\%20SME.pdf

Ozkanli, O., \& Durak, I. (2007). Network organisations in the Turkish textile sector. Problems and Perspectives in Management, 5(2), 142-158.

Pole, K. L., \& Haskell, J. (2002). Managing a modern relationship: Critical factors for business-to-business markets. Proceedings of Academy of Marketing Annual Conference, July 2-5, Nottingham University Business School.

Rindt, J., \& Mouzas, S. (2015). Exercising Power in Asymmetric Relationships: the use of private rules. Industrial Marketing Management, 48(1), 202-213. http://dx.doi.org/10.1016/j.indmarman.2015.03.018

Rogers, D. S., \& Leuschner, R. (2004). Supply chain management: retrospective and prospective. Journal of Marketing Theory and Practice, 12(4), 60-7. http://dx.doi.org/10.1080/10696679.2004.11658533

Rubin, J. Z., \& Brown, B. R. (1975). The social psychology of bargaining and negotiation. New York: Academic Press.

Sollner, A. (1999). Asymmetrical commitment in business relationships. Journal of Business Research, 46(3), 219-233. http://dx.doi.org/10.1016/s0148-2963(98)00039-3

Styles, C., Patterson, P. G., \& Ahmed, F. (2008). A relational model of export performance. Journal of International Business Studies, 39(5), 880-900. http://dx.doi.org/10.1057/palgrave.jibs.8400385

Tokatli, N. (2006). Asymmetrical power relations and upgrading among suppliers of global clothing brands: Hugo Boss in Turkey. Journal of Economic Geography, 7(1), 1-26. http://dx.doi.org/10.1093/jeg/lbl017

Tokatli, N. (2007). Networks, firms, and upgrading within the blue-jeans industry: evidence from Turkey. Global Networks, 7(1), 51-68. http://dx.doi.org/10.1111/j.1471-0374.2006.00156.x

Tokatli, N., \& Kizilgun, O. (2009). From manufacturing garments for ready-to-wear to designing collections for fast fashion: evidence from Turkey. Environment and Planning, 41, 146-162. http://dx.doi.org/10.1068/a4081

Ural, T. (2007). The Antecedents and Consequences of Relationship Quality According to Stages of the Relationship between Exporters and Importers. Problems and Perspectives in Management, 5(3), 111-130.

WTO. (2001). http://www.wto.org/english/news_e/pres11_e/pr628_e.htm

Yin, R. K. (1994). Case study research design and methods. London: Sage Publication.

Yin, R. K. (2003). Case study research: design and methods. London: Sage. 


\section{Copyrights}

Copyright for this article is retained by the author, with first publication rights granted to the journal.

This is an open-access article distributed under the terms and conditions of the Creative Commons Attribution license (http://creativecommons.org/licenses/by/3.0/). 